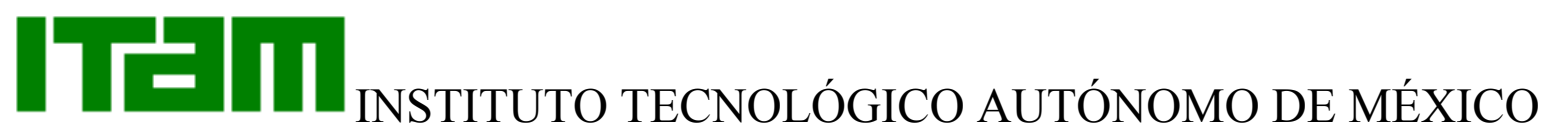

\section{CENTRO DE INVESTIGACIÓN ECONÓMICA}

\section{Discussion Paper Series}

Discount Window Policy, Banking Crises, and Indeterminacy of Equilibrium

Gaetano Antinolfi

Washington University

and

Todd Keister

Instituto Tecnológico Autónomo de México

June 2003

Discussion Paper 03-05

Av. Camino a Santa Teresa \# 930

Col. Héroes de Padierna

México, D.F. 10700

$\mathrm{M}$ E X I C O 


\title{
Discount Window Policy, Banking Crises, and Indeterminacy of Equilibrium ${ }^{1}$
}

\author{
Gaetano Antinolfi \\ Department of Economics, Washington University \\ gaetano@wueconc.wustl.edu \\ Todd Keister \\ Centro de Investigación Económica, ITAM \\ keister@itam.mx
}

June 15, 2003

\begin{abstract}
We examine optimal discount window policy in an economy with a linear investment technology and aggregate liquidity shocks. Unrestricted lending at the discount window prevents large shocks from causing banking crises, but leads to indeterminacy of stationary equilibrium. We show how a policy of offering discount-window loans at an above-market interest rate generates a unique stationary monetary equilibrium. Under such a policy, banking crises occur with positive probability in equilibrium, but a proper choice of interest rate can make the welfare loss due to these crises arbitrarily small. We then modify the model by introducing diminishing returns to investment and show that, in this case, the optimal policy may eliminate banking crises entirely.
\end{abstract}

\footnotetext{
1 We are deeply indebted to Bruce Smith for his useful comments and for many years of encouragement and support. We gratefully acknowledge financial support from the Weidenbaum Center on the Economy, Government, and Public Policy at Washington University. Part of this work was completed while Keister was visiting the University of Texas at Austin, whose hospitality and support is also gratefully acknowledged.
} 


\section{Introduction}

The history of the U.S. banking system is characterized by recurrent episodes in which a shortage of liquidity brought about a crisis and a distortion in the allocation of resources that was believed to have been to some extent avoidable. ${ }^{2}$ These episodes have led to a belief that the smooth and proper functioning of the banking system requires the total supply of currency to change in response to short-term fluctuations in the demand for liquid assets. In fact, one of the main reasons given for the founding of the Federal Reserve System, as stated in the title of the Federal Reserve Act of 1913, was "to furnish an elastic currency." One way of providing an elastic currency is through discount window lending; the monetary authority can offer short-term loans of currency to banks that present illiquid assets as collateral. The terms at which such loans are offered have at least two important effects on the potential scope for liquidity-induced banking crises. First, they have a direct impact on the severity of a crisis; the availability of credit essentially determines how distorted real allocations can become once a crisis is underway. Second, they affect the likelihood of a crisis occurring at any point in time. This is because the terms at which credit will be available if a crisis occurs will influence the amount of liquidity that each bank chooses to hold in its portfolio during "normal" times. This choice, in turn, affects the likelihood that the entire banking system will run out of liquidity and slide into a crisis. In this paper we analyze these two effects within a fully-specified general equilibrium model, and we derive their implications for optimal discount window policy.

A number of existing papers have shown, within a general equilibrium framework, how discount window lending can facilitate the smooth functioning of the banking system and thereby lead to better equilibrium allocations. In Sargent and Wallace [14], for example, the demand for credit fluctuates deterministically and there is a legal restriction on the issue of private credit instruments. In this environment, having a discount window that offers loans at a zero nominal interest rate leads to the existence of a Pareto optimal equilibrium, while closing the discount window does not.

2 See, for instance, the examples described in Champ, Smith, and Williamson [5] and Freeman [9]. Additional historical information on banking crises in the U.S. can be found in Friedman and Schwartz [11], but we should emphasize that interest in the topic is not solely historical. A comprehensive discussion of modern banking crises around the world is provided by Boyd et al. [4]. 
Note that a zero nominal interest rate implies that acquiring liquidity is costless, since currency yields the same return as real (illiquid) assets. Freeman [9] focuses on the role of liquidity in the payments system and shows that attaining an optimal allocation requires the monetary authority to lend sufficient currency in each period to keep the nominal interest rate at zero. ${ }^{3}$ Williamson [18] examines a model with moral hazard where discount window loans can only be made against certain types of assets. The loans that are made again carry a zero nominal interest rate, which minimizes the likelihood of a banking crisis caused by a shortage of liquidity. The important feature common to the environments in these papers is that having a discount window provide costless liquidity improves equilibrium allocations. However, a recent paper by Smith [16] points to a potential danger of following such a policy: it can lead to a "massive" indeterminacy of equilibrium. ${ }^{4}$ The desirability of operating a discount window is then ambiguous; it depends on which of the infinitely-many equilibria would be selected if a discount window were opened.

We begin by studying the same physical environment as Smith [16]. There is an infinite sequence of two-period lived, overlapping generations of agents. A linear investment technology can be used to transform one unit of young-period consumption into a greater amount of old-period consumption. This investment can be liquidated early, but only at a loss. There is also a stock of government-issued fiat currency. An agent is assigned to one of two physically-separated locations at birth, and in each period a fraction of young agents is randomly selected and forced to move to the other location. This fraction is itself a random variable, and is independent across periods. The stochastic relocations in this model act like the portfolio-preference shocks commonly employed in the literature on bank runs, ${ }^{5}$ and banks arise to insure consumers against such uncertainty. Banks take deposits and divide their portfolio between currency and investment. Limited communication prevents claims on specific agents from being traded across locations, and therefore generates a transactions role for currency. Relocated agents must carry with them either currency or liquidated investment. Fluctuations in the number of relocated agents across periods can therefore be interpreted as fluctuations in liquidity demand.

3 A later paper, Freeman [10], adds aggregate financial shocks and compares zero-nominal-rate discount window lending with other ways of providing an elastic currency. See also Schreft and Smith [15], which shows how discount window lending can be superior to open market operations as a policy tool.

4 Smith and Weber [14] study a related environment and show how having an elastic currency generated by private banknote issue can also lead to massive indeterminacy of equilibrium.

5 See, for example, Diamond and Dybvig [7] and the recent papers by Peck and Shell [13] and Ennis and Keister [8]. 
When there is no discount window, Smith [16] identifies a fundamental tension between the stability of the banking system and the efficiency of equilibrium allocations. When the nominal interest rate is positive, banks perceive an opportunity cost of holding cash reserves and therefore economize on such holdings. As a result, the banking system is relatively illiquid and there are recurrent crises in which bank reserves are exhausted and a currency premium emerges. These crises can be avoided entirely if the monetary policy generates a zero nominal interest rate. However, when the nominal interest rate is zero, there is no opportunity cost of holding cash and therefore banks hold sufficient reserves to meet any possible level of liquidity demand. In other words, banks voluntarily become narrow banks and thereby lose their intermediary function. This implies that socially-productive investments are not undertaken and the resulting equilibrium allocation is far from optimal. The underlying source of this tension is that socially-productive investment is illiquid, but agents who are relocated need access to liquid assets. Hence this seems like precisely the type of environment where discount window lending would be a useful policy tool. If, after observing the fraction of agents to be relocated, banks could obtain loans of currency, using their real investments as collateral, they could continue to serve their intermediary function and at the same time crises caused by a shortage of liquid assets could be averted. However, Smith [16] shows that opening a discount window in this environment leads to the existence of a continuum of stationary equilibria, for the following reason. When a bank has access to liquidity at a zero nominal interest rate, it is indifferent between holding liquid assets and making real investments. As a result, any division of banks' portfolios between currency and investment is consistent with equilibrium and hence there are infinitely many (stationary) equilibria, each with a different level of real investment. Some of these equilibria generate higher welfare than closing the discount window, but others generate lower welfare. In other words, the model does not give clear guidance as to whether or not a discount window should be opened. Perhaps the best statement that can be made is that opening a discount window is a "dangerous" policy.

In this paper, we expand the set of discount window policies under consideration and look for an optimal policy in the expanded set. In particular, we move away from the focus on a zero nominal interest rate and allow the monetary authority to set an interest rate at the discount window that is anywhere between the market nominal rate of interest and infinity (in which case the discount window is effectively closed). We show that as long as the interest rate charged on discount window 
loans is higher than the market rate, there is a unique stationary equilibrium in which money has value. In other words, a discount window can be opened without generating indeterminacy as long as borrowing from the discount window is more expensive than holding cash reserves. ${ }^{6}$ However, having a "penalty rate" on discount window loans implies that banking crises will occur in equilibrium, with the frequency and severity of the crises being determined by the size of the penalty. We ask what policy is optimal in terms of generating the highest level of steady-state welfare. We show that penalty-rate policies can be used to generate equilibrium allocations that are arbitrarily close to the first-best allocation, but that no policy can actually implement the first-best allocation. The near-optimal policies entail having low nominal interest rates and nearly-costless liquidity at the discount window.

We then show that the non-existence of an optimal policy is an artifact of the assumption that the return on investment is exactly linear. We replace the investment technology with a standard model of production, thereby bringing the model into the Diamond [6] framework and introducing diminishing returns to investment. Continuing to focus on stationary equilibria, we show that if the diminishing returns are strong enough to create a store-of-value role for money, an optimal policy does exist. This policy entails setting the nominal interest rate to zero and providing discount window loans at this market rate. This policy does not lead to the indeterminacy discussed in Smith [16] precisely because the return on investment is endogenous; only one level of investment will lead to the interest rate required for markets to clear. Hence, in this setting, the optimal monetary policy is a combination of the Friedman rule with a costless-liquidity regime at the discount window.

The remainder of the paper is organized as follows. In the next section we present the details of the basic model and describe in detail the optimal behavior of individual banks. In Section 3 we describe the equilibria of the model under different policy regimes; we present the corresponding welfare analysis in Section 4. In Section 5 we analyze the model with diminishing returns to investment. Finally, in Section 6 we offer some concluding remarks.

\footnotetext{
$6 \quad$ The Federal Reserve System adopted a policy of charging above-market rates on discount window loans in January 2003. Previously, discount window loans were typically granted at below-market rates, with stringent requirements employed to limit access to this credit. Interestingly, this type of policy was also advocated by Bagehot [2], who argued that in times of crisis the monetary authority should act as a lender of last resort and lend freely to the banking system, but "at a penalty rate."
} 


\section{The Model}

In this section we present the model of Smith [16] with the modification that banks can borrow from the discount window at a gross nominal interest rate $\phi$. We briefly describe the physical environment, and then derive the optimal behavior of competitive banks in this environment.

\subsection{The Environment}

Consider an infinite-horizon, overlapping-generations economy with spatial separation. Let $t=$ $0,1,2, \ldots$ index the (discrete) time periods. In each period, a continuum of identical agents with unit mass is born in each of two locations. All agents live for two periods. There is a single consumption good, and each agent is endowed with $w>0$ units of this good when young (and nothing when old). Agents only care about consumption in the second period of life, and have the utility function $u(c)=\ln (c)$. At $t=0$ there is a continuum of old agents (also with unit mass) in each location, each of whom is endowed with $M_{0}$ units of fiat currency.

At the beginning of each period, young agents receive their endowments. At this point, agents (and banks) cannot move between or communicate across locations, and therefore trade only occurs among agents in the same location. Young agents can trade with old agents and can deposit resources in a bank. It is straightforward to show that a young agent will choose to deposit all of her income in a bank. After trade takes place, there is an opportunity to invest goods in a storage technology. This technology transforms one unit of the period- $t$ good into $R>1$ units of the

period $t+1$ good. The other asset in the economy is money. In addition to potentially serving as a store of value, money facilitates transactions made difficult by spatial separation and limited communication (as in Townsend [17]). A bank takes in deposits and allocates its portfolio between currency and investment. Note that the storage technology is the only real investment available in this economy. Goods that are neither consumed nor invested will perish once the investment opportunity has passed.

Next, a fraction $\pi_{t}$ of young agents in each location is notified that they will be moved to the other location. Goods invested in the storage technology cannot be transported between locations unless the investment is first liquidated. A unit of investment that is liquidated yields a return of $r<1$. Limited communication prevents privately-issued liabilities, such as checks, from being verifiable in the other location. Currency, on the other hand, is universally recognizable and 
non-counterfeitable, and is therefore accepted in both locations. Movers are able to contact their bank and withdraw currency and/or liquidated investment. Immediately afterwards, movers are relocated and the next period begins. Movers use the currency they received from the bank to buy consumption in their new location, and at this point all old agents consume and end their lifecycle.

The relocation probability $\pi_{t}$ is a random variable in each period. Since there is a continuum of young agents, it represents both the probability of relocation for each agent and the fraction of all agents who move. That is, $\pi_{t}$ gives the size of the aggregate liquidity shock in period $t$; higher values of $\pi_{t}$ correspond to higher liquidity demand. It has support $[0,1)$ and is drawn from the twice continuously differentiable, strictly increasing distribution function $G$ with associated density function $g$. It is independently and identically distributed over time.

\subsection{Monetary Policy}

The monetary authority has two policy variables, both of which are chosen once and for all in the initial period. First, it sets a (gross) growth rate $\sigma$ for the money supply, so that

$$
M_{t+1}=\sigma M_{t}
$$

holds. These monetary injections/withdrawals take place through lump-sum transfers to young agents; let $\tau_{t}$ denote the real value of the transfer at time $t$. We assume that $\sigma R \geq 1$ holds. In a stationary equilibrium, $\sigma R$ will be the value of the nominal interest rate; hence we are ruling out policies that would lead money to have a strictly higher return than investment. The qualitative properties of equilibrium under such a policy would be very similar to the case where $\sigma R=1$ holds; excluding these policies simplifies the presentation without any loss of economic insight.

Second, the monetary authority sets a (gross) nominal interest rate $\phi>1$ on discount window loans. ${ }^{7}$ Note that this policy is always feasible in the sense that it requires no real resources from the monetary authority regardless of how the price level changes over time. If, in period $t$, a bank demands a loan of $\lambda_{t}$ (measured in real terms, per unit of deposits), it goes to the discount window and receives $\lambda_{t} p_{t}$ dollars, where $p_{t}$ is the general price level. ${ }^{8}$ In the following period, the bank must pay back $\phi \lambda_{t} p_{t}$ dollars. We assume that the monetary authority destroys $\lambda_{t} p_{t}$ of these dollars and uses the remaining $(\phi-1) \lambda_{t} p_{t}$ to purchase goods. In this way, the stock of currency in

\footnotetext{
$7 \quad$ In Section 5 we relax this condition to $\phi \geq 1$.

8 Throughout the analysis, we only consider equilibria where money has value and hence $p_{t}$ is finite for all $t$.
} 
circulation continues to obey (1). We assume that agents derive no utility from the revenue earned by the monetary authority through this lending policy. As will become clear later, if instead the revenue were rebated to agents as a state-contingent, lump-sum payment, our main results would not change. Such rebates complicate the derivations substantially, so we present the simpler case here.

\subsection{Banks}

A young agent deposits her entire savings $w+\tau_{t}$ with a bank. The bank promises her a return $d_{t}^{m}\left(\pi_{t}\right)$ if she is relocated and a return $d_{t}\left(\pi_{t}\right)$ if she is not. As the notation indicates, both of these returns can depend on the size of the aggregate liquidity shock. It is assumed that banks behave competitively in the sense that they $(i)$ take the real return on assets as given and $(i i)$ choose the deposit return schedules $d_{t}^{m}$ and $d_{t}$ to maximize the expected utility of young lenders. Per unit of deposits, the bank acquires an amount $\gamma_{t}$ of real money balances and invests the remaining $1-\gamma_{t}$. A fraction $\delta_{t}$ of this investment is liquidated early and given to movers while the remaining $\left(1-\delta_{t}\right)$ is held until maturity and given to non-movers. In addition, the bank borrows a non-negative (real) amount $\lambda_{t}$ from the discount window. The bank faces two constraints on the return schedules it can offer. First, relocated agents must be given currency or liquidated investment. Let $\alpha_{t}\left(\pi_{t}\right)$ denote the fraction of the bank's reserves that are given to movers. Using the fact that the return to holding money between periods $t$ and $t+1$ is given by $\left(p_{t} / p_{t+1}\right)$, we have that

$$
\pi_{t} d_{t}^{m}\left(\pi_{t}\right)=\alpha_{t}\left(\pi_{t}\right) \gamma_{t} \frac{p_{t}}{p_{t+1}}+\delta_{t}\left(\pi_{t}\right)\left(1-\gamma_{t}\right) r+\lambda_{t}\left(\pi_{t}\right) \frac{p_{t}}{p_{t+1}}
$$

must hold. The second constraint is that payments to non-movers cannot exceed the value of the bank's remaining portfolio - remaining cash reserves plus matured investment minus the repayment of the discount window loan. Since the investment gives the gross real rate of return $R$, this constraint can be written as

$$
\left(1-\pi_{t}\right) d_{t}\left(\pi_{t}\right)=\left[1-\alpha_{t}\left(\pi_{t}\right)\right] \gamma_{t} \frac{p_{t}}{p_{t+1}}+\left[1-\delta_{t}\left(\pi_{t}\right)\right]\left(1-\gamma_{t}\right) R-\lambda_{t}\left(\pi_{t}\right) \phi \frac{p_{t}}{p_{t+1}}
$$

Banks maximize a typical depositor's expected utility subject to these two constraints. Each bank 
will therefore choose the functions $d_{t}^{m}$ and $d_{t}$ to maximize

$$
\int_{0}^{1}\left(\pi \ln \left[d_{t}^{m}(\pi)\left(w+\tau_{t}\right)\right]+(1-\pi) \ln \left[d_{t}(\pi)\left(w+\tau_{t}\right)\right]\right) g(\pi) d \pi
$$

subject to (2) and (3). Let $I_{t}=R_{t}\left(p_{t+1} / p_{t}\right)$ denote the (gross) nominal interest rate. That is, $I_{t}$ reflects the additional return that investment offers over currency, and hence represents the opportunity cost of holding cash reserves. Substituting in the two constraints and performing some manipulations, the bank's problem can be written as

$$
\begin{aligned}
& \int_{0}^{1} \pi \ln \left[\alpha_{t}(\pi) \gamma_{t}+\delta_{t}(\pi)\left(1-\gamma_{t}\right) I_{t} \frac{r}{R}+\lambda_{t}(\pi)\right] g(\pi) d \pi+ \\
& \int_{0}^{1}(1-\pi) \ln \left[\left[1-\alpha_{t}(\pi)\right] \gamma_{t}+\left[1-\delta_{t}(\pi)\right]\left(1-\gamma_{t}\right) I_{t}-\lambda_{t}(\pi) \phi\right] g(\pi) d \pi
\end{aligned}
$$

subject to

$$
\begin{aligned}
& 0 \leq \gamma_{t} \leq 1, \quad 0 \leq \alpha_{t}(\pi) \leq 1, \quad 0 \leq \delta_{t}(\pi) \leq 1, \text { and } \\
& 0 \leq \lambda_{t}(\pi) \leq \frac{1}{\phi}\left(\left[1-\alpha_{t}(\pi)\right] \gamma_{t}+\left[1-\delta_{t}(\pi)\right]\left(1-\gamma_{t}\right) I_{t}\right) \text { for all } \pi .
\end{aligned}
$$

Note that the fractions of currency reserves and investment paid out to movers, as well as the amount of discount-window borrowing, are chosen after the realization of $\pi_{t}$, while the fraction of currency in the bank's asset portfolio is chosen before the realization of $\pi_{t}$. Hence we can solve the problem backward, by first finding the optimal values of $\alpha_{t}, \delta_{t}$, and $\lambda_{t}$ as functions of $\gamma_{t}$ and $\pi_{t}$. That is, we can first choose $\left(\alpha_{t}, \delta_{t}, \lambda_{t}\right)$ to

$$
\begin{array}{ll}
\operatorname{maximize} & \pi_{t} \ln \left[\alpha_{t} \gamma_{t}+\delta_{t}\left(1-\gamma_{t}\right) I_{t} \frac{r}{R}+\lambda_{t}\right]+ \\
& \left(1-\pi_{t}\right) \ln \left[\left(1-\alpha_{t}\right) \gamma_{t}+\left(1-\delta_{t}\right)\left(1-\gamma_{t}\right) I_{t}-\lambda_{t} \phi\right]
\end{array}
$$

subject to the constraints above. We begin the process of solving this problem by showing that, outside of one knife-edge case, the bank may respond to high liquidity demand either by liquidating investment or by borrowing from the discount window, but not both.

Proposition 1 If $\phi<R / r$ holds, then the solution to (5) has $\delta_{t}=0$ for all values of $\gamma_{t}$ and $\pi_{t}$. If $\phi>R / r$ holds, then the solution to (5) has $\lambda_{t}=0$ for all values of $\gamma_{t}$ and $\pi_{t}$.

The proof of this proposition is contained in the appendix, but the intuition is straightforward. Borrowing from the discount window and liquidating investment are both ways to generate ad- 
ditional consumption for movers as a group (at the expense of non-movers). Moreover, both of these methods have a constant marginal cost, in that the amount of consumption taken away from non-movers for each unit of consumption given to movers is independent of the quantity borrowed or liquidated. Therefore, the bank will only use the less costly of the two methods. If the interest rate at the discount window is low, then borrowing is less costly and banks will never liquidate investment. If the interest rate at the discount window is high enough, however, then liquidation is less costly and the discount window will be inactive. In the latter case, our model reduces to that presented in Smith [16]. There is one borderline case that the proposition does not cover, when $\phi$ is exactly equal to $R / r$. In this case the solution to (5) is not unique, because the bank is indifferent between liquidating investment and borrowing from the discount window. In what follows, we will largely ignore this knife-edge case in order to simplify the exposition. We show in section 4 below that setting $\phi=R / r$ cannot be part of an optimal policy.

Using Proposition 1, we can break (5) into two cases and solve each one separately. When $\phi<R / r$ holds, the solution sets $\delta_{t}$ to zero for all values of $\pi_{t}$ and sets

$$
\begin{gathered}
\alpha_{t}\left(\pi_{t}\right)=\left\{\begin{array}{c}
\pi_{t}\left(1+\frac{1-\gamma_{t}}{\gamma_{t}} I_{t}\right) \\
1 \\
1
\end{array}\right\} \text { and } \lambda_{t}\left(\pi_{t}\right)=\left\{\begin{array}{c}
0 \\
0 \\
\pi_{t}\left(1-\gamma_{t}\right)\left(\frac{I_{t}}{\phi}\right)-\left(1-\pi_{t}\right) \gamma_{t}
\end{array}\right\} \\
\text { for } \pi_{t} \in\left\{\begin{array}{c}
{\left[0, \pi^{*}\right)} \\
{\left[\pi^{*}, \pi^{* *}\right)} \\
{\left[\pi^{* *}, 1\right)}
\end{array}\right\},
\end{gathered}
$$

where we have

$$
\pi^{*}=\frac{\gamma_{t}}{\gamma_{t}+\left(1-\gamma_{t}\right) I_{t}}
$$

and

$$
\pi^{* *}=\frac{\gamma_{t}}{\gamma_{t}+\left(1-\gamma_{t}\right) \frac{I_{t}}{\phi}} .
$$

When demand for liquidity is fairly low (the relocation shock is below a critical value $\pi^{*}$ ), the bank is able to give movers and non-movers the same return by paying out only a fraction of its reserves to movers. Since the bank wants to provide agents with insurance against the relocation shock, this is the optimal thing to do. When the realization of the relocation shock is greater than $\pi^{*}$, however, this is no longer feasible. In this case, there are so many movers that even if all of the bank's cash reserves are given to them, they will receive a lower return than the (relatively 
few) non-movers. Following Champ, Smith, and Williamson [5], we label such an event a banking crisis. In a crisis, the bank has an incentive to borrow currency from the discount window so that it can transfer resources from non-movers to movers. However, such borrowing is costly and, as a result, the bank waits until the number of movers is above a second critical level $\pi^{* *}$ before doing any.

Some intuition for the range of inaction $\left[\pi^{*}, \pi^{* *}\right]$ can be gained by thinking about the set of feasible ways for the bank to divide resources between movers (as a group) and non-movers (as a group), once $\gamma_{t}$ has been chosen. One action that is always feasible is to give all cash reserves (which will be worth $\gamma_{t}\left(p_{t} / p_{t+1}\right)$ in real terms next period) to movers and the return from all investment (worth $\left(1-\gamma_{t}\right) R$ ) to non-movers. If instead the bank wants to give fewer resources to movers and more to non-movers (perhaps because there are very few movers this period), it can do so on a one-for-one basis. That is, for every unit of future consumption (in the form of currency) that is taken away from movers, exactly one unit is given to non-movers. Now suppose that instead the bank wants to give more resources to movers and fewer to non-movers. In this case the bank must either liquidate investment or obtain a loan from the discount window, so that for every unit of additional consumption given to movers, non-movers must give up either $R / r$ or $\phi$ units. This difference in the rates of transformation is what leads to the range of inaction $\left[\pi^{*}, \pi^{* *}\right]$ in the optimal levels of $\alpha_{t}$ and $\lambda_{t}$. When there are very few movers, the optimal action is to give almost all of the resources to non-movers and hence we are in the region where the rate of transformation is unity. As we examine larger and larger realizations of $\pi_{t}$, the solution gives more and more of the bank's currency reserves to movers. At $\pi_{t}=\pi^{*}$, the optimal action reaches the kink in the constraint set where all currency reserves are given to movers. This point remains the optimal choice for a range of values of $\pi_{t}$; only when the realization is greater than $\pi^{* *}$ is it optimal to move to the steeper-sloped part of the boundary. In conjunction with (8), this reasoning also demonstrates how the interest rate on discount window loans determines the potential severity of crises when $\phi<R / r$ holds. The more costly it is to borrow, the larger $\pi_{t}$ must be (and therefore the larger the gap between the returns of movers and non-movers will be) before a bank starts borrowing to ease the crisis.

We now proceed to solve for the optimal value of $\gamma_{t}$. To do so, we substitute the optimal values of $\alpha_{t}$ and $\delta_{t}$ into the bank's objective function so that the only remaining variable to be determined 
is $\gamma_{t}$. The problem can then be written as

$$
\begin{aligned}
\max _{0 \leq \gamma_{t} \leq 1} & \int_{0}^{\pi^{*}} \ln \left[\gamma_{t}+\left(1-\gamma_{t}\right) I_{t}\right] g(\pi) d \pi \\
& +\int_{\pi^{*}}^{\pi^{* *}}\left[\pi \ln \left(\gamma_{t}\right)+(1-\pi) \ln \left(1-\gamma_{t}\right)\right] g(\pi) d \pi \\
& +\int_{\pi^{* *}}^{1} \ln \left[\gamma_{t}+\left(1-\gamma_{t}\right) \frac{I_{t}}{\phi}\right] g(\pi) d \pi .
\end{aligned}
$$

Because borrowing is costly, the solution to this problem will be interior as long as $1<I_{t}<\phi$ holds. The first-order condition is given by

$$
\begin{aligned}
& \frac{I_{t}-1}{\gamma_{t}+\left(1-\gamma_{t}\right) I_{t}} G\left(\pi^{*}\right)+\frac{\frac{I_{t}}{\phi}-1}{\gamma_{t}+\left(1-\gamma_{t}\right) \frac{I_{t}}{\phi}}\left[1-G\left(\pi^{* *}\right)\right] \\
= & \frac{1}{\gamma_{t}} \int_{\pi^{*}}^{\pi^{* *}} \pi g(\pi) d \pi-\frac{1}{1-\gamma_{t}} \int_{\pi^{*}}^{\pi^{* *}}(1-\pi) g(\pi) d \pi,
\end{aligned}
$$

which can be reduced to

$$
\gamma_{t}=\pi^{* *}-\int_{\pi^{*}}^{\pi^{* *}} G(\pi) d \pi .
$$

This equation implicitly defines the solution to the bank's portfolio allocation problem (recall that $\gamma_{t}$ appears in the expressions for $\pi^{*}$ and $\pi^{* *}$ above) as a function of the variable $I_{t} \in(1, \phi)$. Let $\gamma_{\phi}\left(I_{t}\right)$ denote this solution, where the $\phi$ subscript indicates that the solution $(i)$ applies in the region of the parameter space where the discount window is active and $(i i)$ depends on the interest rate charged on discount window loans. The next proposition establishes some properties of this solution.

Proposition 2 For any given $\phi \in(1, R / r)$ and any $I_{t}>0$, the bank's problem has a unique solution. The reserve-deposit ratio $\gamma_{\phi}$ in this solution is a continuous function of $I_{t}$ and satisfies:

$$
\begin{array}{ll}
\text { (a) } & \gamma_{\phi}\left(I_{t}\right)=1 \text { for } I_{t} \leq 1, \\
\text { (b) } & \gamma_{\phi}\left(I_{t}\right)=0 \text { for } I_{t} \geq \phi, \text { and } \\
\text { (c) } & \gamma_{\phi}^{\prime}\left(I_{t}\right)<0 \text { for } I_{t} \in(1, \phi) .
\end{array}
$$

The proof of this proposition is contained in the appendix; the intuition is again fairly straightforward. If $I_{t} \leq 1$ holds, then the return on currency is at least a high as the return on investment. Since currency offers the additional advantage of being liquid, banks will hold only currency. If $I_{t} \geq \phi$ holds, on the other hand, then borrowing from the discount window costs no more than 
holding cash reserves. The quantity of borrowing can be chosen after the demand for liquidity is known, and therefore banks will hold no cash reserves. For intermediate values of $I_{t}$, banks will hold both types of assets, with the fraction of resources placed in currency being a decreasing function of $I_{t}$.

We now examine the solution to the bank's problem when $\phi>R / r$ holds. In this case, we know from Proposition 1 that the discount window is inactive, and hence the problem is the same as that studied in Smith [16]. The solution sets

$$
\begin{gathered}
\alpha_{t}\left(\pi_{t}\right)=\left\{\begin{array}{c}
\pi_{t}\left(1+\frac{1-\gamma_{t}}{\gamma_{t}} I_{t}\right) \\
1 \\
1
\end{array}\right\} \text { and } \delta_{t}\left(\pi_{t}\right)=\left\{\begin{array}{c}
0 \\
0 \\
\pi_{t}-\left(1-\pi_{t}\right) \frac{\gamma_{t}}{1-\gamma_{t}} \frac{R}{r} \frac{1}{I_{t}}
\end{array}\right\} \\
\text { for } \pi_{t} \in\left\{\begin{array}{c}
{\left[0, \pi^{*}\right)} \\
{\left[\pi^{*}, \bar{\pi}\right)} \\
{[\bar{\pi}, 1)}
\end{array}\right\},
\end{gathered}
$$

where $\pi^{*}$ is again given by (7) and we have

$$
\bar{\pi}=\frac{\gamma_{t}}{\gamma_{t}+\left(1-\gamma_{t}\right) I_{t} \frac{r}{R}}
$$

When $1<I_{t}<R / r$ holds, the optimal choice of $\gamma_{t}$ is interior and is implicitly defined by

$$
\gamma_{t}=\bar{\pi}-\int_{\pi^{*}}^{\bar{\pi}} G(\pi) d \pi
$$

Let $\gamma_{\ell}\left(I_{t}\right)$ denote this solution, where the $\ell$ subscript indicates that this solution applies in the region of parameter space where liquidation takes places (and the discount window is inactive). The following is a combination of our Proposition 1 with Proposition 3 in Smith [16].

Proposition 3 Given any $\phi>R / r$ and any $I_{t}>0$, the bank's problem has a unique solution. The reserve-deposit ratio $\gamma_{\ell}$ in this solution is a continuous function of $I_{t}$ and satisfies

(a) $\gamma_{\ell}\left(I_{t}\right)=1$ for $I_{t} \leq 1$,

(b) $\gamma_{\ell}\left(I_{t}\right)=0$ for $I_{t}>\frac{R}{r}$, and

(c) $\gamma_{\ell}^{\prime}\left(I_{t}\right)<0$ for $I_{t} \in\left(1, \frac{R}{r}\right)$.

Having solved the optimization problem of the bank, we turn to an analysis of general equilibrium. 


\section{Equilibrium}

An equilibrium of this economy is characterized by the market-clearing condition for real balances. Since the supply of real money balances is equal to $M_{t} / p_{t}$ and the demand for real balances comes entirely from banks, market clearing requires that we have

$$
\frac{M_{t}}{p_{t}}=\left(w+\tau_{t}\right) \gamma_{t} \text {. }
$$

The government's budget constraint can be written as

$$
\tau_{t}=\frac{M_{t}-M_{t-1}}{p_{t}}=\frac{\sigma-1}{\sigma} \frac{M_{t}}{p_{t}} .
$$

Define $z_{t} \equiv M_{t} / p_{t}$ to be the (per-capita) level of real balances in the economy. Then, if money has value (that is, if the price level is finite), we have

$$
\frac{p_{t}}{p_{t+1}}=\frac{1}{\sigma} \frac{z_{t+1}}{z_{t}}
$$

and hence the market nominal rate of interest is given by

$$
I_{t}=\sigma R \frac{z_{t}}{z_{t+1}}
$$

We can then re-write (11) as

$$
z_{t}=\left(w+\frac{\sigma-1}{\sigma} z_{t}\right) \gamma_{i}\left(\sigma R \frac{z_{t}}{z_{t+1}}\right)
$$

where the function $\gamma_{i}$ is given by either $\gamma_{\phi}$ or $\gamma_{\ell}$, depending on the rate of interest charged at the discount window. When $\phi>R / r$ holds, $\gamma_{i}$ is given by $\gamma_{\ell}$ and this dynamical system is the same as that studied by Smith [16]. When $\phi<R / r$ holds, however, $\gamma_{i}$ is instead given by $\gamma_{\phi}$ and the dynamical system is different.

Following Smith [16], we focus on stationary equilibria, where $z_{t+1}=z_{t}=z$ holds for all $t$. In such an equilibrium the nominal interest rate is given by $I_{t}=\sigma R$ and the level of real balances by

$$
z^{*}=\frac{\sigma w \gamma_{i}(\sigma R)}{\sigma-(\sigma-1) \gamma_{i}(\sigma R)}
$$

This expression demonstrates that a stationary equilibrium with valued fiat currency exists if and only if $\gamma_{i}(\sigma R)>0$ holds. In other words, the monetary authority must set its two policies in such 
a way that banks demand a positive amount of reserves. Using Propositions 2 and 3, a necessary and sufficient condition for this to be the case is that

$$
\sigma R<\min \left(\phi, \frac{R}{r}\right)
$$

hold. If (13) did not hold, either borrowing from the discount window or liquidating investment would be a cheaper way of providing liquidity than holding cash reserves. The demand for cash reserves would then be zero and money would have no value. In addition, (12) demonstrates that, when (13) holds, there is a unique positive level of real money balances consistent with stationary equilibrium. Again referring back to Propositions 2 and 3, we see that the stationary monetary equilibrium allocation will therefore be unique except in the knife-edge case where $\phi=R / r$ holds and the bank is indifferent between borrowing and liquidating. We summarize these results in the following proposition.

Proposition 4 If (13) holds, there exists a unique positive stationary equilibrium level of real money balances. In addition, as long as $\phi \neq R / r$ holds, there is a unique stationary monetary equilibrium allocation.

In a sense, this statement is the central result of the paper. Discount window lending does not lead to indeterminacy of stationary equilibrium in this environment if discount window loans carry a "penalty" rate of interest. This result contrasts strongly with that reported in Smith [16] for the case where $\phi=1$ holds. When the net nominal interest rate at the discount window is zero, borrowing from the discount window has the same cost as does holding cash reserves. However, borrowing has the advantage that the quantity can be chosen after the bank observes how many depositors are moving. Therefore the bank will be unwilling to hold any cash reserves unless there is no opportunity cost of doing so, that is, unless $I_{t}=1$ holds. If $I_{t}=1$ holds, however, the bank is completely indifferent between holding reserves and borrowing from the discount window, and this indeterminacy in the solution to the bank's problem translates into an indeterminacy of equilibrium prices and allocations. When $\phi>I_{t}$ holds, however, borrowing from the discount window is more costly than holding cash reserves. We have shown that this implies that there is a unique, interior level of demand for cash reserves, which in turn generates a unique stationary monetary equilibrium. 


\section{Banking Crises and Welfare}

We now turn to the question of how discount window policy affects the frequency and the severity of banking crises. We continue to focus entirely on stationary monetary equilibria, and hence maintain the assumption that (13) holds. Recall that a banking crisis occurs whenever movers and non-movers receive different returns. For all but one policy choice, banking crises will occur in equilibrium.

Proposition 5 If $\sigma R=1$ holds, then banking crises never occur in equilibrium. If $\sigma R>1$ holds, however, then banking crises occur with positive probability in equilibrium.

This result follows directly from Propositions 2 and 3, using the fact that in a stationary equilibrium $I_{t}=\sigma R$ must hold. When $I_{t}=1$ holds, banks will set $\gamma_{t}$ to unity and therefore will have sufficient cash reserves to meet any level of liquidity demand. When $I_{t}>1$ holds, on the other hand, banks will set $\gamma_{t}$ less than unity, and therefore with positive probability the realized value of $\pi_{t}$ will be greater than $\pi^{*}$. Because $\phi>1$ holds, it follows from (7) and (8) that such a value of $\pi_{t}$ will necessarily lead to a crisis.

The severity of a crisis depends on the realized value of $\pi_{t}$ and on the interest rate at the discount window. From Proposition 1 we know that setting $\phi$ below $R / r$ guarantees that (costly) liquidation of investment will never take place. Within this range, $\phi$ also determines how distorted the real allocation of resources can become. From (6) we can calculate the largest possible difference between the returns given to movers and to non-movers, which is a measure of the maximum potential severity of a crisis. For values of $\pi_{t}$ greater than $\pi^{* *}$, we have

$$
d_{t}^{m}=\gamma_{t} \frac{1}{\sigma}+\left(1-\gamma_{t}\right) \frac{R}{\phi} \quad \text { and } \quad d_{t}=\gamma_{t} \frac{\phi}{\sigma}+\left(1-\gamma_{t}\right) R
$$

The difference between these two expressions is strictly increasing in $\phi$. In other words, a lower interest rate on discount window loans implies a better "worst case scenario" in terms of the distortion of real allocations. This happens because a lower interest rate makes banks more willing to borrow currency and thereby transfer resources from non-movers to movers during a crisis.

We now turn to the optimal policy question: How should a benevolent government set the policy pair $(\sigma, \phi)$ ? Following Smith [16], we take the objective to be the steady-state utility of a young agent. 9 We begin by discussing the "first-best" allocation in this environment. Consider

\footnotetext{
$9 \quad$ That is, we ignore the initial old generation in our welfare calculations. See footnote 9 in Smith [16] on this issue.
} 
the problem of a social planner who directly controls investment and allocation decisions in both locations and who therefore is essentially unaffected by the relocation friction. It should be clear that this planner has no use for money and hence will place the total endowment in each period into storage. When the stored goods mature, the planner will divide the proceeds equally among the (now-old) agents in each location, regardless of their place of birth. The utility level of a young agent in this allocation is given by $\ln (R w)$. Notice that we are not claiming that this allocation can be achieved in the decentralized economy with relocation and information frictions. Our intention here is merely to present this allocation as a useful benchmark.

We now present our main result of this section. While no policy can implement the first-best allocation described above, there are policies that can implement arbitrarily near-by allocations without introducing indeterminacy of stationary equilibrium.

Proposition 6 For any $\varepsilon>0$, there exists a policy $(\sigma, \phi)$ such that steady-state welfare in the unique stationary monetary equilibrium generated by $(\sigma, \phi)$ is within $\varepsilon$ of the first-best value $\ln (R w)$.

The proof is contained in the appendix; the intuition is as follows. Getting very close to the firstbest allocation requires having nearly all of the economy's total endowment placed into storage. (so that the value of real money balances held by banks $z^{*}$ is close to zero). A bank will only be willing to hold very little currency if borrowing from the discount window is relatively inexpensive, that is, if $\phi$ is very close to unity. In order for a stationary monetary equilibrium to exist and be unique, we need $1<\sigma R<\phi$ to hold, and hence for $\sigma R$ to be very close to unity. In the proof in the appendix, we show that a sequence of policies $\left(\sigma_{j}, \phi_{j}\right)$ can be constructed so that, along this sequence, the allocation in the unique stationary monetary equilibrium converges uniformly to the first-best allocation described above. Note that the first-best allocation itself cannot be implemented. Achieving the first-best allocation requires that all of the economy's resources be placed into storage, which implies that there must be zero demand for cash reserves and hence money must have no value. When money has no value, discount window lending is clearly ineffective. What Proposition 6 shows is that a "good" policy in this environment is to make the demand for cash reserves very small, and to use the discount window to provide almost-costless liquidity. ${ }^{10}$

\footnotetext{
10 The result that having a low interest rate on discount window loans is a good policy is not driven by our assumption that agents derive no utility from the revenue made by the monetary authority on these loans. Because a low-interestrate policy can bring the economy very close to the first-best allocation, it is better than a high-interest-rate policy regardless of how this revenue is used.
} 
The last statement points out what is perhaps an important distinction between money and liquidity. Money is an asset that is inherently liquid, but a demand for liquidity does not necessarily imply a demand for money. In fact, the benefit of having a discount window in this environment derives precisely from the fact that it helps meet the liquidity needs of relocated agents in a way that does not prevent socially-productive investments from being undertaken. ${ }^{11}$ The non-existence of an optimal policy comes from the fact that there is no other role for money in this setting. To demonstrate that this is the case, we now change the investment technology in such a way that money is useful as a store of value (as in Diamond [6]). We show that, in this case, there is a welldefined optimal policy and that this policy can be viewed as an implementation of the Friedman rule.

\section{Diminishing Returns and the Friedman Rule}

We now change the technology in the model so that there are decreasing returns to investment. We do this by replacing the storage technology with a production technology that uses capital and labor as inputs. We should emphasize that the particular way in which we modify the model is not important for our main message. Any method of introducing diminishing returns to investment that are "strong enough" will deliver the same result (for example, one could have intra-generational consumption loans, as in Champ, Smith, and Williamson [5] and Antinolfi, Huybens, and Keister [1]). We have chosen to add production to the model because it entails making minimal modifications to the basic structure, and because it places the model within the well-known Diamond [6] framework.

At the beginning of each period, perfectly competitive firms use capital and labor to produce output using a constant-returns-to-scale technology

$$
Y_{t}=F\left(k_{t}, n_{t}\right)
$$

where $k_{t}$ is total capital input and $n_{t}$ total labor input. The function $F$ satisfies the usual concavity

\footnotetext{
11 In this way, Proposition 6 is closely related to the results of Bhattacharya, Haslag, and Russell [3] on the optimality of the Friedman rule. They study a model where the fraction of agents relocated is the same in every period and there is no discount window. They show that, as in Smith [16], a money growth rate rule that leads to a zero nominal interest rate is not optimal because it generates too little real investment. They then construct a "simulator regime" policy under which money is valued but holding money does not preclude real investment. Under this regime a zero nominal interest rate is optimal.
} 
and Inada conditions. For simplicity, we assume that capital depreciates completely in production. Agents are no longer endowed with goods; instead, each young agent is endowed with one unit of time. This time is supplied inelastically as labor, and hence the income of a young agent is equal to the real wage, denoted by $w_{t}$. In place of the storage technology used above, one unit of consumption placed into investment at time $t$ now yields one unit of capital at time $t+1$. The timing of events within a period is the same as that described in Section 2. In particular, investment decisions must be made before the size of the relocation shock $\pi_{t}$ is known. Investment can be liquidated after $\pi_{t}$ has been realized, in which case it yields $r<1$ units of consumption. In all other ways, the model is exactly the same as before. Young agents find it optimal to deposit all of their income in a bank, and the bank places a fraction $\gamma_{t}$ of its portfolio in currency and the remaining $\left(1-\gamma_{t}\right)$ in investment. The bank's problem is unchanged. The only real difference that adding production brings to the model is that the return on investment (as well as the income of young agents) depends on the aggregate level of investment.

Since the size of the population (and hence of the labor force) is normalized to unity, the equilibrium factor-pricing relationships can be written as

$$
w_{t}=f\left(k_{t}\right)-k_{t} f^{\prime}\left(k_{t}\right) \equiv w\left(k_{t}\right)
$$

and

$$
R_{t}=f^{\prime}\left(k_{t}\right)
$$

where $f\left(k_{t}\right) \equiv F\left(k_{t}, 1\right)$ is the intensive production function and $R_{t}$ denotes the period-t rental price of capital. Note that the real return on goods invested in period $t$ is given by $R_{t+1}$.

Our goal is to compare the policy prescriptions of this model with those derived for the linearstorage model in Section 4. For this reason we only consider stationary allocations, which are easily compared with allocations in the earlier model. We begin by finding the optimal stationary allocation, and then we ask if there exists a policy choice under which it is the unique stationary monetary equilibrium allocation. The exercise is as before: we examine the problem of a social planner whose objective is to maximize the steady-state utility level of a young agent. We allow the planner to choose the initial level of the capital stock, and impose the constraint that the level of capital be the same for all periods. ${ }^{12}$ Letting $k^{*}$ denote the optimal stationary quantity of capital,

12 We should stress that this emphasis on stationarity is only to facilitate the comparison of allocations in this model with those in the linear-storage model. If the initial level of capital were fixed arbitrarily, then typically the optimal 
the planner will set

$$
f^{\prime}\left(k^{*}\right)=1 \text {. }
$$

In other words, $k^{*}$ will be set according to the golden rule, because this plan maximizes the total amount of consumption available to the planner in each period. The planner will distribute this consumption exactly the same way as in the earlier model: in each location, the total amount of consumption available will be divided evenly among the old agents, regardless of their place of birth. The level of consumption given to each agent will be equal to $f\left(k^{*}\right)-k^{*}$. Using (14) and (15), we can then write the utility level of an agent in this allocation as $\ln \left(w\left(k^{*}\right)\right)$. Notice that this is essentially the same expression as that given in Section 4 for the optimal utility level in the linear-storage model, but with $R$ set to unity. An agent's consumption is independent of her relocation status and of $\pi_{t}$, and is equal to the value of her young-period endowment multiplied by the rate of return on investment ( $R$ in the linear storage model, unity in the optimal stationary allocation here).

We now investigate under what conditions this optimal allocation can be implemented as an equilibrium by the proper choice of monetary policy. The analysis in the previous sections demonstrates that such a policy must have $\phi=1$. Only when borrowing at the discount window is costless will banks choose to offer perfect insurance against relocation. Setting $\phi=1$ requires setting $\sigma$ so that $\sigma R_{t}=1$ holds, and hence our candidate optimal policy is $(\sigma, \phi)=(1,1)$. We now look at the set of stationary monetary equilibria generated by this policy, under the assumption that the initial level of the capital stock is given by $k^{*}$.

Under the candidate optimal policy, the solution to the bank's problem is slightly different than that described in Section 2. The values of $\alpha_{t}$ and $\lambda_{t}$ given in (6) are still an optimal choice. ${ }^{13}$ However, the solution to (9), the problem of choosing $\gamma_{t}$, is now degenerate. Because $\phi=1$ holds, all agents will receive the average return on the bank's portfolio regardless of the realization of $\pi_{t}$, and hence $\gamma_{t}$ will be chosen to maximize this return. If the optimal stationary allocation is implemented, then the return on both money and investment will be unity, which means that a bank will be completely indifferent between any two levels of $\gamma_{t}$ in $[0,1]$. The equilibrium conditions

allocation would involve growth (or decay) toward a steady state. The results we present below would still hold in such a setting, but their relationship to the results in Section 4 would be less evident.

13 There are other optimal choices, but they all lead to the same allocation of consumption. For example, the bank could set $\alpha_{t}(\pi)$ to zero for all $\pi$ and pay movers the same real return with currency borrowed from the discount window, and then use its cash reserves to repay the loan. 
under the candidate optimal policy are therefore $(i)$ a no-arbitrage condition stating that money and investment yield the same return

$$
\frac{p_{t}}{p_{t+1}}=f^{\prime}\left(k_{t+1}\right)
$$

and $($ ii) a materials-balance condition stating that all savings takes place either in money or in investment

$$
k_{t+1}+z_{t}=w\left(k_{t}\right)
$$

Because $\sigma=1$ holds, we have

$$
\frac{p_{t}}{p_{t+1}}=\frac{z_{t+1}}{z_{t}}
$$

and therefore the equilibrium laws of motion for $\left(k_{t}, z_{t}\right)$ are given by

$$
k_{t+1}=w\left(k_{t}\right)-z_{t}
$$

and

$$
z_{t+1}=f^{\prime}\left(w\left(k_{t}\right)-z_{t}\right) z_{t} .
$$

It immediately follows from these two expressions that the level of capital in a stationary monetary equilibrium must be equal to $k^{*}$. The level of real money balances must satisfy

$$
z^{*}=w\left(k^{*}\right)-k^{*}
$$

and therefore if a stationary monetary equilibrium exists under this policy, it is unique. The answer to our question of whether or not the policy implements the optimal stationary allocation depends crucially on the sign of $z^{*}$. If $z^{*}$ is negative, then

$$
f^{\prime}\left(w\left(k_{t}\right)\right)>1
$$

holds. Since $w\left(k^{*}\right)$ is the maximum amount of investment that can occur in equilibrium (when $k^{*}$ is the level of capital), in this case the return on investment is always greater than unity. This is analogous to the assumption $R>1$ in the linear-storage model, and implies that money cannot have value in equilibrium when $(\sigma, \phi)=(1,1)$ holds. As in Section 4 , the optimal stationary allocation cannot be implemented (but policies with $\phi>1$ can implement arbitrarily nearby allocations). The basic problem is the same as that identified in the linear-storage model: There is no 
role for money in the model outside of the provision of liquidity. The optimal allocation requires that no money be held, but then liquidity cannot be provided through the discount window.

If $z^{*}$ is positive, however, then

$$
f^{\prime}\left(w\left(k_{t}\right)\right)<1
$$

holds, which implies that money has a store-of-value role (and prevents capital over-accumulation). ${ }^{14}$ In the unique stationary monetary equilibrium, both money and capital offer a return of unity and therefore all agents have a consumption level of $w\left(k^{*}\right)$. Hence in this case the policy $(\sigma, \phi)=$ $(1,1)$ does implement the optimal stationary allocation. We state this result as our final proposition.

Proposition 7 Define $z^{*}$ as in (16). If $z^{*}>0$ holds, then the allocation in the unique stationary monetary equilibrium under the policy $(\sigma, \phi)=(1,1)$ is equal to the optimal stationary allocation.

This result verifies that the non-existence of an optimal policy in Section 4 was caused by the linearity of the investment technology and the fact that there was no role for money in the model other than to provide liquidity for relocated agents. If there is a role for money as a store of value, as in the Diamond-type model presented above, then costless liquidity can be provided at the discount window without undermining the demand for cash reserves, and an optimal policy does exist. This optimal policy can be viewed as an implementation of the Friedman rule, where currency and investment offer the same return and banks are given access to costless liquidity through the discount window. This policy does not lead to indeterminacy of stationary equilibrium because only one level of real investment $\left(k^{*}\right)$ will lead to the rate of return required for banks to be willing to hold both assets.

\section{Concluding Remarks}

We have presented a general equilibrium model in which discount window lending is a useful policy tool for attenuating the effects of systemic banking crises. The previous literature has focused on lending at a zero nominal interest rate, and shown how such lending can prevent real allocations from becoming distorted during periods of high liquidity demand. However, Smith [16] identified a source of instability associated with the free provision of liquidity: indeterminacy of stationary equilibrium. The environment presented in Section 2 is one where, as in Smith

\footnotetext{
14 A positive value of $z^{*}$ is analogous to having a "Samuelson case" economy as defined by Gale [12], while a
} negative value is analogous to having a "classical case" economy. 
[16], a policy of freely providing discount window loans at a zero nominal interest rate leads to a continuum of stationary equilibria, each with a different level of real investment. Our main result is that, in this environment, charging a penalty rate on discount window loans leads to a unique stationary equilibrium in which money has value. In other words, much of the benefit of having an elastic currency can be obtained without generating indeterminacy, provided that the discount window lends at above-market rates. Such a penalty-rate policy does lead to the occurrence of banking crises in equilibrium, but by setting a small enough penalty the monetary authority can make both the probability of a crisis occurring in each period and the welfare loss when a crisis occurs arbitrarily small. In addition, we showed that an important source of the indeterminacy of stationary equilibrium that arises under a costless-liquidity policy is the linearity in the investment technology. When investment instead displays decreasing returns to scale and money has a storeof-value role, providing liquidity at a zero nominal interest rate allows the economy to achieve the first-best allocation as the unique stationary monetary equilibrium. In this case the optimal policy is a combination of the Friedman rule and a free-liquidity regime at the discount window.

The specific policy prescriptions of our analysis obviously depend on the specific features of the environment that we consider. In particular, the only uncertainty in our model is about liquidity demand. There is no uncertainty about the real value of a bank's assets or a bank's ability to repay a discount window loan. An interesting question concerns the optimal lending policy when the economy is also affected by solvency shocks, ${ }^{15}$ and whether or not such shocks would lead to a strictly positive penalty rate being optimal. If the optimal discount window policy involves a positive penalty rate, the optimal money-growth rate may differ from the Friedman rule. Another important friction that is absent from our framework is asymmetric information. It is often pointed out that the presence of lender of last resort services may generate moral hazard, resulting in excessive risk taking by banks and therefore greater uncertainty about a bank's ability to repay the loan. ${ }^{16}$ Again, it would be interesting to see if such a change in the environment would lead to an optimal policy that involves charging a strictly positive penalty rate on discount window loans. We leave these questions for future research.

\footnotetext{
15 In a different environment, Freeman [10] studies this problem and finds that a zero-nominal-rate lending policy should be combined with quantity restrictions at the discount window. See also Antinolfi, Huybens, and Keister [1] on the role of quantity restrictions.

16 Williamson [18] studies a model in which there is moral hazard and shows that in this setting discount window lending at a zero nominal interest rate is welfare improving.
} 


\section{Appendix A. Proofs of Propositions}

Proposition 1: If $\phi<R / r$ holds, then the solution to (5) has $\delta_{t}=0$ for all values of $\gamma_{t}$ and $\pi_{t}$. If $\phi>R / r$ holds, then the solution to (5) has $\lambda_{t}=0$ for all values of $\gamma_{t}$ and $\pi_{t}$.

Proof: The derivatives of the objective function (5) with respect to the three choice variables are

$$
\begin{aligned}
& \frac{\partial}{\partial \alpha_{t}}: \frac{\pi_{t} \gamma_{t}}{\alpha_{t} \gamma_{t}+\delta_{t}\left(1-\gamma_{t}\right) I_{t} \frac{r}{R}+\lambda_{t}}-\frac{\left(1-\pi_{t}\right) \gamma_{t}}{\left(1-\alpha_{t}\right) \gamma_{t}+\left(1-\delta_{t}\right)\left(1-\gamma_{t}\right) I_{t}-\lambda_{t} \phi} \\
& \frac{\partial}{\partial \delta_{t}}: \frac{\pi_{t}\left(1-\gamma_{t}\right) I_{t} \frac{r}{R}}{\alpha_{t} \gamma_{t}+\delta_{t}\left(1-\gamma_{t}\right) I_{t} \frac{r}{R}+\lambda_{t}}-\frac{\left(1-\pi_{t}\right)\left(1-\gamma_{t}\right) I_{t}}{\left(1-\alpha_{t}\right) \gamma_{t}+\left(1-\delta_{t}\right)\left(1-\gamma_{t}\right) I_{t}-\lambda_{t} \phi} \\
& \frac{\partial}{\partial \lambda_{t}}: \frac{\pi_{t}}{\alpha_{t} \gamma_{t}+\delta_{t}\left(1-\gamma_{t}\right) I_{t} \frac{r}{R}+\lambda_{t}}-\frac{\left(1-\pi_{t}\right) \phi}{\left(1-\alpha_{t}\right) \gamma_{t}+\left(1-\delta_{t}\right)\left(1-\gamma_{t}\right) I_{t}-\lambda_{t} \phi} \text {. }
\end{aligned}
$$

Suppose that $\phi<R / r$ holds. For the solution to have $\delta_{t}>0$, we need (A-2) to be non-negative. However, this would imply that both (A-1) and (A-3) are strictly positive, and therefore that the solution must have $\alpha_{t}$ and $\lambda_{t}$ at their maximum possible values. In other words, it must be the case that no resources are kept for non-movers, so that $d_{t}=0$ holds. Given this, it is straightforward to show that $d_{t}^{m}$ is strictly decreasing in $\delta_{t}$ (because an increase in liquidation implies a corresponding decrease in discount window borrowing, and liquidation is more costly). Therefore, the solution cannot have $\delta_{t}>0$.

Now suppose that $\phi>R / r$ holds. For the solution to have $\lambda_{t}>0$, we need (A-3) to be nonnegative. This would imply that both (A-1) and (A-2) are strictly positive, and therefore that the solution must have $\alpha_{t}=1$ and $\delta_{t}=1$. However, the bank would then have no resources left at time $t+1$ with which to repay the loan, and therefore the upper bound on $\lambda_{t}$ would be zero. Hence the solution cannot have $\lambda_{t}>0$.

Proposition 2: For any given $\phi \in(1, R / r)$ and any $I_{t}>0$, the bank's problem has a unique solution. The reserve-deposit ratio $\gamma_{\phi}$ in this solution is a continuous function of $I_{t}$ and satisfies:

$$
\begin{aligned}
& \text { (a) } \gamma_{\phi}\left(I_{t}\right)=1 \text { for } I_{t} \leq 1, \\
& \text { (b) } \gamma_{\phi}\left(I_{t}\right)=0 \text { for } I_{t} \geq \phi, \text { and } \\
& \text { (c) } \gamma_{\phi}^{\prime}\left(I_{t}\right)<0 \text { for } I_{t} \in(1, \phi) .
\end{aligned}
$$

Proof: We know from Proposition 1 that in this case $\delta_{t}=0$ holds for all $\pi_{t}$. Let $M\left(\gamma_{t}, I_{t}\right)$ denote the objective function in (9). We begin by establishing part $(c)$. The solution to the bank's problem 
is implicitly defined by the necessary (and sufficient) condition

$$
M_{1}\left(\gamma_{t}, I_{t}\right)=0 .
$$

In addition, concavity of the objective function with respect to $\gamma_{t}$ implies that, at the solution,

$$
M_{11}\left(\gamma_{t}, I_{t}\right)<0
$$

must hold. The first-order condition can be re-written in the form

$$
\gamma_{t}=\pi^{* *}\left(\gamma_{t}, I_{t}\right)-\int_{\pi^{*}\left(\gamma_{t}, I_{t}\right)}^{\pi^{* *}\left(\gamma_{t}, I_{t}\right)} G(\pi) d \pi
$$

where the functions $\pi^{*}$ and $\pi^{* *}$ are as defined in (7) and (8). The effect of a change in $I_{t}$ on the optimal value of $\gamma_{t}$ is determined by implicit differentiation of the identity

$$
M_{1}\left(\gamma\left(I_{t}\right), I_{t}\right) \equiv 0
$$

which yields

or

$$
M_{11}\left(\gamma\left(I_{t}\right), I_{t}\right) \frac{d \gamma\left(I_{t}\right)}{d I_{t}}+M_{12}\left(\gamma\left(I_{t}\right), I_{t}\right)=0,
$$

$$
\frac{d \gamma\left(I_{t}\right)}{d I_{t}}=-\frac{M_{12}\left(\gamma\left(I_{t}\right), I_{t}\right)}{M_{11}\left(\gamma\left(I_{t}\right), I_{t}\right)}
$$

We know that $M_{11}\left(\gamma\left(I_{t}\right), I_{t}\right)<0$ must hold at the solution to the problem. In addition, writing the first derivative of the objective in the form (A-4) and then differentiating with respect to $I_{t}$, we obtain

$$
M_{12}\left(\gamma\left(I_{t}\right), I_{t}\right)=\frac{-\left(1-\gamma_{t}\right) \frac{\gamma_{t}}{\phi}}{\left[\gamma_{t}+\left(1-\gamma_{t}\right) \frac{I_{t}}{\phi}\right]^{2}}-\left\{\begin{array}{c}
G\left(\frac{\gamma_{t}}{\gamma_{t}+\left(1-\gamma_{t}\right) I_{t}}\right) \frac{\left(1-\gamma_{t}\right) \gamma_{t}}{\left[\gamma_{t}+\left(1-\gamma_{t}\right) I_{I_{t}}\right.} \\
-G\left(\frac{\gamma_{t}}{\gamma_{t}+\left(1-\gamma_{t}\right) \frac{I_{t}}{\phi}}\right) \frac{\left(1-\gamma_{t}\right) \frac{\gamma_{t}}{\phi}}{\left[\gamma_{t}+\left(1-\gamma_{t}\right) \frac{I_{t}}{\phi}\right]^{2}}
\end{array}\right\}
$$

or

$$
M_{12}\left(\gamma\left(I_{t}\right), I_{t}\right)=\frac{\frac{1}{\phi} \gamma_{t}\left(1-\gamma_{t}\right)}{\left[\gamma_{t}+\left(1-\gamma_{t}\right) \frac{I_{t}}{\phi}\right]^{2}}\left[G\left(\pi^{* *}\right)-1\right]-G\left(\pi^{*}\right) \frac{\gamma_{t}\left(1-\gamma_{t}\right)}{\left[\gamma_{t}+\left(1-\gamma_{t}\right) I_{t}\right]^{2}}<0 .
$$

Therefore, we have that

$$
\frac{d \gamma\left(I_{t}\right)}{d I_{t}}<0
$$


holds, and part $(c)$ of the proposition is verified.

Next, consider again the first-order condition

$$
M_{1}\left(\gamma\left(I_{t}\right), I_{t}\right) \equiv \frac{\gamma_{t}}{\gamma_{t}+\left(1-\gamma_{t}\right) \frac{I_{t}}{\phi}}-\gamma\left(I_{t}\right)-\int_{\pi^{*}\left(\gamma_{t}, I_{t}\right)}^{\pi^{* *}\left(\gamma_{t}, I_{t}\right)} G(\pi) d \pi=0
$$

Rewrite the equation as

$$
M_{1}\left(\gamma\left(I_{t}\right), I_{t}\right) \equiv \frac{1}{\gamma_{t}+\left(1-\gamma_{t}\right) \frac{I_{t}}{\phi}}\left[\frac{1}{\left(1-\gamma_{t}\right)}\right]-\frac{1}{\left(1-\gamma_{t}\right)}-\frac{1}{\gamma_{t}\left(1-\gamma_{t}\right)} \int_{\pi^{*}\left(\gamma_{t}, I_{t}\right)}^{\pi^{* *}\left(\gamma_{t}, I_{t}\right)} G(\pi) d \pi=0
$$

or

$$
M_{1}\left(\gamma\left(I_{t}\right), I_{t}\right) \equiv\left[\frac{1}{\left(1-\gamma_{t}\right)}\right]\left[\frac{1}{\gamma_{t}+\left(1-\gamma_{t}\right) \frac{I_{t}}{\phi}}-1\right]-\frac{1}{\gamma_{t}\left(1-\gamma_{t}\right)} \int_{\pi^{*}\left(\gamma_{t}, I_{t}\right)}^{\pi^{* *}\left(\gamma_{t}, I_{t}\right)} G(\pi) d \pi=0
$$

or

$$
M_{1}\left(\gamma\left(I_{t}\right), I_{t}\right) \equiv\left[\frac{1-\frac{I_{t}}{\phi}}{\gamma_{t}+\left(1-\gamma_{t}\right) \frac{I_{t}}{\phi}}\right]-\frac{1}{\gamma_{t}\left(1-\gamma_{t}\right)} \int_{\pi^{*}\left(\gamma_{t}, I_{t}\right)}^{\pi^{* *}\left(\gamma_{t}, I_{t}\right)} G(\pi) d \pi=0 .
$$

Using L'Hôpital's rule, we can show that

$$
\lim _{\gamma_{t} \rightarrow 1} \frac{1}{\gamma_{t}\left(1-\gamma_{t}\right)} \int_{\pi^{*}\left(\gamma_{t}, I_{t}\right)}^{\pi^{* *}\left(\gamma_{t}, I_{t}\right)} G(\pi) d \pi=\lim _{\gamma_{t} \rightarrow 1} \frac{1}{\left(1-\gamma_{t}\right)-\gamma_{t}}\left[G\left(\pi^{* *}\right) \frac{d \pi^{* *}}{d \gamma_{t}}-G\left(\pi^{*}\right) \frac{d \pi^{*}}{d \gamma_{t}}\right]
$$

holds, and hence that

$$
\lim _{\gamma_{t} \rightarrow 1} \frac{1}{\left(1-\gamma_{t}\right)-\gamma_{t}}\left[\begin{array}{c}
G\left(\frac{\gamma_{t}}{\gamma_{t}+\left(1-\gamma_{t}\right) \frac{I_{t}}{\phi}}\right) \frac{\frac{I_{t}}{\phi}}{\left[\gamma_{t}+\left(1-\gamma_{t}\right) \frac{I_{t}}{\phi}\right]^{2}}- \\
G\left(\frac{\gamma_{t}}{\gamma_{t}+\left(1-\gamma_{t}\right) I_{t}}\right) \frac{I_{t}}{\left[\gamma_{t}+\left(1-\gamma_{t}\right) I_{t}\right]^{2}}
\end{array}\right]=I_{t}\left(1-\frac{1}{\phi}\right)
$$

holds. We therefore have

$$
\begin{aligned}
\lim _{\gamma_{t} \rightarrow 1} M_{1}\left(\gamma\left(I_{t}\right), I_{t}\right) & =1-\frac{I_{t}}{\phi}-I_{t}\left(1-\frac{1}{\phi}\right)= \\
& =1-\frac{I_{t}}{\phi}-I_{t}+\frac{I_{t}}{\phi}=1-I_{t} .
\end{aligned}
$$

Of course, we must still have

$$
\lim _{\gamma_{t} \rightarrow 1} M_{1}\left(1, I_{t}\right)=0
$$


which implies that $I_{t}=1$ must hold. Hence, we have established $\gamma(1)=1$. In addition, the (negative) monotonicity of $\gamma_{t}$ with respect to $I_{t}$ implies that $\gamma\left(I_{t}\right)=1$ also holds for all values of $I_{t} \leq 1$. This completes the proof of part $(a)$.

Finally, again applying L'Hôpital's rule to the first-order condition we obtain

$$
\begin{aligned}
& \lim _{\gamma_{t} \rightarrow 0} \frac{1}{\gamma_{t}\left(1-\gamma_{t}\right)} \int_{\pi^{*}\left(\gamma_{t}, I_{t}\right)}^{\pi^{* *}\left(\gamma_{t}, I_{t}\right)} G(\pi) d \pi=\lim _{\gamma_{t} \rightarrow 0} \frac{1}{\left(1-\gamma_{t}\right)-\gamma_{t}}\left[G\left(\pi^{* *}\right) \frac{d \pi^{* *}}{d \gamma_{t}}-G\left(\pi^{*}\right) \frac{d \pi^{*}}{d \gamma_{t}}\right]= \\
& =\lim _{\gamma_{t} \rightarrow 0} \frac{1}{\left(1-\gamma_{t}\right)-\gamma_{t}}\left[\begin{array}{c}
G\left(\frac{\gamma_{t}}{\gamma_{t}+\left(1-\gamma_{t}\right) \frac{I_{t}}{\phi}}\right) \frac{\frac{I_{t}}{\phi}}{\left[\gamma_{t}+\left(1-\gamma_{t}\right) \frac{I_{t}}{\phi}\right]^{2}}- \\
G\left(\frac{\gamma_{t}}{\gamma_{t}+\left(1-\gamma_{t}\right) I_{t}}\right) \frac{I_{t}}{\left[\gamma_{t}+\left(1-\gamma_{t}\right) I_{t}\right]^{2}}
\end{array}\right]=G(0) \frac{1}{\frac{I_{t}}{\phi}}-G(0) \frac{1}{I_{t}}=0 .
\end{aligned}
$$

Therefore we have

$$
\lim _{\gamma_{t} \rightarrow 0} M_{1}\left(\gamma\left(I_{t}\right), I_{t}\right)=\lim _{\gamma_{t} \rightarrow 0}\left[\frac{1-\frac{I_{t}}{\phi}}{\gamma_{t}+\left(1-\gamma_{t}\right) \frac{I_{t}}{\phi}}\right]=\frac{1-\frac{I_{t}}{\phi}}{\frac{I_{t}}{\phi}} .
$$

Recall that $M_{1}\left(\gamma\left(I_{t}\right), I_{t}\right)=0$ must hold at the solution, and hence we have

$$
\frac{1-\frac{I_{t}}{\phi}}{\frac{I_{t}}{\phi}}=0
$$

This equation immediately implies that $I_{t}=\phi$ must hold. Thus we have shown that $\gamma(\phi)=0$ holds, and monotonicity of $\gamma_{t}$ with respect to $I_{t}$ implies that $\gamma\left(I_{t}\right)=0$ also holds for all $I_{t} \geq \phi$. This proves part $(b)$ and completes the proof of the proposition.

Proposition 6: For any $\varepsilon>0$, there exists a policy $(\sigma, \phi)$ such that steady-state welfare in the unique stationary equilibrium generated by $(\sigma, \phi)$ is within $\varepsilon$ of the first-best value $\ln (R w)$.

Proof: Fix any sequence $\left\{\phi_{j}\right\}_{j=1}^{\infty}$ of discount-window interest rates such that $1<\phi_{j}<R / r$ holds for all $j$ and we have

$$
\lim _{j \rightarrow \infty} \phi_{j}=1 .
$$

Next, fix a sequence $\left\{\bar{\gamma}_{j}\right\}_{j=1}^{\infty}$ of reserve-deposit ratios such that $0<\bar{\gamma}_{j}<1$ holds for all $j$ and we have

$$
\lim _{j \rightarrow \infty} \bar{\gamma}_{j}=0
$$

For each $j$, find the money growth rate $\sigma_{j}$ that would lead banks to choose $\bar{\gamma}_{j}$ as their reserve- 
deposit ratio. That is, choose $\sigma_{j}$ to satisfy

$$
\gamma_{\phi_{j}}\left(\sigma_{j} R\right)=\bar{\gamma}_{j}
$$

From Proposition 2 we know that such a value of $\sigma_{j}$ always exists. Furthermore, because $\bar{\gamma}_{j}$ is strictly between zero and unity, we must have

$$
1<\sigma_{j} R<\phi_{j}
$$

for all $j$, and therefore the sequence $\left\{\sigma_{j}\right\}$ must converge to $1 / R$.

Using Proposition 4 and the fact that $\phi_{j}<R / r$ holds, we have that each policy $\left(\sigma_{j}, \phi_{j}\right)$ generates a unique steady-state allocation. From (6) it is straightforward to show that in a stationary equilibrium both

and

$$
\gamma_{t} \frac{1}{\sigma}+\left(1-\gamma_{t}\right) \frac{R}{\phi} \leq d_{t}^{m}\left(\pi_{t}\right) \leq \gamma_{t} \frac{1}{\sigma}+\left(1-\gamma_{t}\right) R
$$

$$
\gamma_{t} \frac{1}{\sigma}+\left(1-\gamma_{t}\right) R \leq d_{t}\left(\pi_{t}\right) \leq \gamma_{t} \frac{\phi}{\sigma}+\left(1-\gamma_{t}\right) R
$$

hold for all $\pi_{t} \in[0,1]$. These two expressions show that as $\bar{\gamma}_{j}$ converges to zero and $\phi$ to unity, the functions $d_{t}^{m}$ and $d_{t}$ both converge uniformly to the constant function $R$. This implies that the expected utility level of a young agent along the sequence of policies $\left(\sigma_{j}, \phi_{j}\right)$ converges to $\ln (R w)$, which establishes the result. 


\section{REFERENCES}

[1] Antinolfi, Gaetano, Elisabeth Huybens, and Todd Keister (2001) Monetary stability and liquidity crises: The role of the lender of last resort. Journal of Economic Theory 99, 187-219.

[2] Bagehot, Walter (1873) Lombard Street: A Description of the Money Market. London: William Clowes and Sons.

[3] Bhattacharya, Joydeep, Joseph H. Haslag, and Steven Russell (2003) When and why is the Friedman rule optimal? mimeo.

[4] Boyd, John H., Pedro Gomis, Sungkyu Kwak, and Bruce D. Smith (2001) A user's guide to banking crises. mimeo.

[5] Champ, Bruce, Bruce D. Smith, and Stephen D. Williamson (1996) Currency elasticity and banking panics: Theory and evidence. Canadian Journal of Economics 29, 828-864.

[6] Diamond, Peter A. (1965) National debt in a neoclassical growth model. American Economic Review 55, 1126-1150.

[7] Diamond, Douglas W. and Philip H. Dybvig (1983) Bank runs, deposit insurance, and liquidity. Journal of Political Economy 91, 401-419.

[8] Ennis, Huberto M. and Todd Keister (2003) Economic growth, liquidity, and bank runs. Journal of Economic Theory 109, 220-245.

[9] Freeman, Scott (1996) The payments system, liquidity, and rediscounting. American Economic Review 86, 1126-1138.

[10] Freeman, Scott (1999) Rediscounting under aggregate risk. Journal of Monetary Economics 43, 197-216.

[11]Friedman, Milton and Anna J. Schwartz (1963) A Monetary History of the United States, 1867-1960. Princeton, NJ: Princeton University Press.

[12] Gale, David (1973) Pure exchange equilibrium of dynamic economic models. Journal of Economic Theory 6, 12-36.

[13] Peck, James and Karl Shell (2003) Equilibrium bank runs. Journal of Political Economy 111, 103-123.

[14] Sargent, Thomas J. and Neil Wallace (1982) The real-bills doctrine versus the quantity theory: A reconsideration. Journal of Political Economy 90, 1212-1236.

[15] Schreft, Stacey L. and Bruce D. Smith (2002) The conduct of monetary policy with a shrinking stock of government debt. Journal of Money, Credit, and Banking 34, 848-882.

[16] Smith, Bruce D. (2002) Monetary Policy, Banking Crises, and the Friedman Rule. American Economic Review 92, 128-134.

[17] Townsend, Robert M. (1987) Economic organization with limited communication. American Economic Review 77, 954-971.

[18] Williamson, Stephen D. (1998) Discount window lending and deposit insurance. Review of Economic Dynamics 1, 246-275. 